\title{
Epidemiological evidence relating snus to health - an updated review based on recent publications
}

Peter $N$ Lee

\begin{abstract}
An earlier review summarized evidence relating use of snus (Swedish-type moist snuff) to health and to initiation and cessation of smoking. This update considers the effect recent publications on snus use and health have on the overall evidence. The additional evidence extends the list of neoplastic conditions unassociated with snus use (oropharynx, oesophagus, stomach, lung) to include colorectal cancer and acoustic neuroma, and further undermines the weakly-based argument that snus use increases the risk of pancreatic cancer, although there is a report of poorer cancer survival in users. It remains undemonstrated that "snuff-dipper's lesion" increases risk of oral cancer, and recent publications add to the evidence that snus use has no effect on periodontitis or dental caries. Although onset of acute myocardial infarction is not adversely associated with snus use, there is some evidence of an association with reduced survival. Whether this is a direct effect of snus use or a result of confounding by socioeconomic status or other factors requires further investigation, as does a report of an increased risk of heart failure in snus users. Even if some adverse health effects of snus use do exist, it remains clear that they are far less than those of smoking.
\end{abstract}

Keywords: Cancer, Oral disease, Circulatory disease, Tobacco, Smokeless

\section{Review}

\section{Background}

Swedish-type moist snuff ("snus") consists of finely ground air- or sun-cured tobacco, salt (sodium chloride), water, humidifying agents, chemical buffering agents (sodium carbonate), and food-grade flavourings. It is manufactured using a heat treatment process and, because of the manufacturing methods and selection of snus tobaccos, has stable levels of certain unwanted constituents, such as tobacco-specific nitrosamines, which are low compared to smokeless products prevalent on the US market, such as US-style moist snuff $[1,2]$. A pinch (or dip) of snus is placed between the gum and upper lip, often for 11 to 14 hours daily [3], in contrast to US finely cut moist snuff (or chewing tobacco) which is held (or chewed) in the gingival buccal area [4]. Use of snus involves nicotine exposure similar to and perhaps somewhat greater than that from smoking [5-11].

Correspondence: PeterLee@pnlee.co.uk

P N Lee Statistics and Computing Ltd, Sutton, Surrey SM2 5DA, United Kingdom
Although the sale of snus is banned in other EU countries, Sweden has a derogation, partly due to its long history of use.

In recent years there has been considerable interest in snus as a possible safer alternative to smoking. However, attention has been drawn to possible health effects of snus use. A review in 2008 for the EC [12] referred to its carcinogenicity, citing the pancreas as a major target organ, to the localized oral lesions it causes, and to possible risks of oral cancer and acute myocardial infarction (AMI). Following a series of reviews of the effects of smokeless tobacco on the various specific diseases of interest in which I was involved [4,13-16] I published, in 2011, a comprehensive review, including meta-analysis, of the epidemiological evidence relating snus to health [17]. My review concluded that "the evidence provides scant support for any major adverse health effects of snus". Among my detailed conclusions I noted that the overall data showed no association of snus with heart disease or stroke or with various types of cancer (oropharynx, oesophagus, stomach, lung) and that the characteristic 
"snuff dipper's lesion" [18] does not predict oral cancer. For pancreatic cancer, the evidence, as discussed more fully elsewhere [15] is limited and difficult to interpret, but overall does not show a statistically significant increased risk, either for never smokers, or for the whole population (with adjustment for smoking).

Since my comprehensive review [17] appeared I became aware of two more recent publications providing major new findings, one on pancreatic cancer [19], the other on AMI [20], diseases which are particularly relevant to the debate concerning the safety or otherwise of snus. It was therefore felt important to update my review, taking into account not only these two papers, but also other recent publications on snus use and health, in order to determine the effect they had on the overall conclusions. The update is limited to neoplastic conditions, circulatory disease (CID) and oral conditions.

\section{Methods}

Methods are as previously described [17], with searches updated to 18th November 2012. Results are only summarized for health effects where new relevant publications could be identified.

\section{Results}

Nine new relevant publications were identified [19-27].

\section{Pancreatic cancer}

An earlier review of smokeless tobacco and risk of pancreatic cancer [15] considered nine North American and two Scandinavian studies. Seven of these provided estimates of the relative risk (RR) associated with smokeless tobacco use, based on data for smokers and nonsmokers combined, and with adjustment for smoking (the "smoking-adjusted relative risk") and five provided estimates based on data for never smokers. Meta-analysis gave a combined estimate of the smoking-adjusted RR of 1.07 (95\% confidence interval [CI] 0.71-1.60), and of 1.23 (95\% CI 0.67-2.31) for the risk in never smokers. While there was little evidence of an increase in the North American studies, the two Scandinavian studies showed rather more indication of an increase. One [28] reported a significant increase $(2.00,95 \%$ CI $1.20-3.30)$ in never smokers, but not $(0.90,95 \%$ CI $0.70-1.20)$ in the smoking-adjusted analysis. The other [29], conducted in Norway, reported no increase $(0.85,95 \%$ CI $0.24-3.07)$ in never smokers, but did report a significant increase $(1.67,95 \%$ CI $1.12-1.50)$ in the smoking-adjusted analysis. This study has been criticized [30-33] for various reasons, including failure to adjust for alcohol, using an exposed group which included a completely different type of smokeless tobacco (skrá) as well as snus, and a very long follow-up with no updating of tobacco use. The EC report [12] misleadingly reported only the significant associations, leading to their conclusion that the pancreas was a main "target organ", ignoring the fact that the combined evidence from those two studies did not show a significant increase, either for never smokers (1.61, 95\% CI $0.77-3.34)$ or based on the smokingadjusted RRs (1.20, 95\% CI 0.66-2.20).

While there are no new studies on pancreatic cancer and snus, attention should be drawn to a recent paper [19] reporting the results of a pooled analysis relating pancreatic cancer to the use of forms of smokeless tobacco other than snus, based on 11 case-control studies, none in Scandinavia. Compared to never users of tobacco, the odds ratio (OR) was estimated as 0.98 (95\% CI $0.75-1.27$ ) for ever smokeless tobacco users and 0.62 (95\% CI 0.37-1.04) for smokeless tobacco only users. Although it has been argued [34] that the case-control studies are subject to bias for various reasons, and that the two cohort studies [29,35] are "strong", it would nevertheless seem that these results strengthen the argument that snus use is unassociated with an increased pancreatic cancer risk, especially since nitrosamine levels are substantially lower in snus than in other types of smokeless tobacco [36], nitrosamines being considered "the major and most abundant group of carcinogens" in smokeless tobacco products [12].

One must conclude that the evidence for an association of snus with pancreatic cancer, already weakly based before the pooled analysis [19], has become even more weakly based.

\section{Oral cancer}

The direct epidemiological evidence previously considered [17] found no increased risk of oropharyngeal cancer associated with snus use, either in never smokers (RR 1.01, 95\% CI 0.71-1.45, $\mathrm{n}=4$ ) or based on smokingadjusted results (RR 0.97, 95\% CI 0.68-1.37, $\mathrm{n}=7$ ), a result supported by long-term follow-up of 1115 individuals with snuff-dippers lesion, which observed no cancers at the site of lesions seen initially [37]. It is also consistent with evidence of a lack of increased risk associated with smokeless tobacco use in US populations in studies published since $1990[4,16]$.

A recent paper [21] described 16 male patients with oral squamous cell carcinoma seen in seven Swedish hospitals, with the cancers reported to have occurred at the "exact anatomical location" where snus had been used for several years. The authors concluded that "Swedish snuff may not be a harmless alternative to smoking". The difficulty in interpreting these results is that there is no control information on the distribution of sites among other oral cancer patients who used snus, or among patients who did not use snus, so that one cannot judge whether oral cancer is more likely than expected to be seen at the site of use. Even if snus does 
lead to some oral cancers at the site of use, the epidemiological evidence strongly suggests that any increased risk is small, and substantially less than that associated with smoking.

\section{Colorectal cancer}

A recent study [22] is the first to report results relating to a possible association of snus with colon or rectal cancer. The study involved follow-up to 2007 of 336,381 male Swedish construction workers for whom detailed information on tobacco use at cohort entry had been collected in 1971-1992. Age- and BMI- adjusted RRs comparing pure snus users and non-users of any tobacco were presented by duration of use, but no evidence of an association was seen for cancers of the colon (based on $\mathrm{n}=153$ cases in users), or the rectum $(\mathrm{n}=97)$, separate results being also presented for the right- and left-sided colon ( $\mathrm{n}=59$ and 60 respectively). Anal cancers were also studied, but only one case was seen in users. Some limitations of the Construction Workers Study, which has reported results for many health endpoints, are discussed elsewhere [17].

\section{Acoustic neuroma}

At the time of my earlier review [17], there was no evidence relating snus use to acoustic neuroma. A recent paper [24] described a study in Sweden conducted in 2002 to 2007, involving 451 cases and 710 populationbased controls. Risk of acoustic neuroma, adjusted for education and tobacco use, was unassociated with current snus use (OR 0.94, 95\% CI 0.57-1.55) or former snus use (OR 1.22, 95\% CI 0.71-2.10). This contrasted with a marked reduction in risk associated with current smoking (OR 0.41, 95\% CI 0.23-0.74), prompting the authors to suggest that protection may be conferred by a constituent of tobacco smoke other than nicotine.

\section{Survival from cancer}

A recent paper [23] concerns survival from cancer among 40,320 male Swedish construction workers, 24,826 of whom had died. Compared to never tobacco users, an increased risk of death was evident in all tobacco groups studied after adjustment for age at diagnosis, period of diagnosis, cancer site and BMI, whether the death was from the primary cancer or another cause. The RR of overall mortality was 1.13 (95\% CI 1.05-1.20) for pure snus users, 1.21 (1.17-1.25) for pure smokers and 1.17 (1.12-1.22) for combined users. For causespecific mortality RRs for pure snus users $(1.15,1.05$ 1.26) and pure smokers $(1.15,1.10-1.21)$ were similar. The authors comment on their inability to control for stage of cancer at diagnosis, though did show that the increased mortality in pure snus users was similar in those with or without comorbidity. The authors noted that the mechanism behind the poorer survival in pure snus users warranted further investigation, and suggested that "nicotine may play a role".

\section{Circulatory disease}

Table four of my earlier review [17] summarized results relating snus use to ischaemic heart disease (IHD), AMI, stroke and any CID separately for never smokers and for the whole population with adjustment for smoking. None of the meta-analysis RR estimates were significant $(\mathrm{p}<0.05)$ or exceeded 1.10 and I concluded that "although a small effect of snus on the incidence of CID cannot be excluded, this has not been demonstrated by the available epidemiological data".

A recent paper [20] describes the results of a pooled analysis from eight prospective observational studies of the relationship of snus use to AMI, based on men who never smoked. Table 1 summarizes the total evidence relating snus use in male never smokers incorporating this latest data, and excluding those results reported earlier [38-40] which are superseded by the later individual study results given for the pooled analysis. Based on the 13 individual estimates of RR/OR the combined fixed effect estimate is 1.07 (95\% CI 0.98-1.16). However, there is significant $(\mathrm{p}=0.06)$ heterogeneity, and the randomeffects estimate is 1.06 (95\% CI 0.91-1.23). The major contributor to the heterogeneity is the individual estimate of 1.35 (95\% CI 1.13-1.62) from the analysis of the Construction Workers Study based on interviews in 1971-1974. The heterogeneity may well have arisen because the results for this study relate to a period when the form of snus used was different. Also, during 197174 , the data collected by questionnaire were limited for snus use and ambiguously coded for smoking [17]. Furthermore, it is the only estimate based only on fatal cases. Restricting attention to the other 12 estimates, the combined fixed effect estimate becomes 1.00 (95\% CI 0.91-1.10) with no statistical evidence of heterogeneity.

While these results seem consistent with a lack of effect of snus use on AMI, it should be noted that the pooled analysis [20], though reporting no association of snus use with the combined incidence of fatal and nonfatal AMI (RR 1.04, 95\% CI 0.93-1.17) and no significant association with level or duration of use, did report that the short-term fatality rate "appeared increased" in snus users (OR 1.28, 95\% CI 0.99-1.68). However the authors noted that this relationship "may be due to confounding by socioeconomic or life style factors", and that confounding by level of education could not be addressed in this analysis due to lack of relevant data.

Results relating to the short-term fatality rate were not presented by study, but it seems clear that they largely depended on the findings from the Construction Workers Study which contributed $88 \%$ of the total 
Table 1 RR/OR of IHD/AMI for current (vs. never) snus use in never smoking Swedish men

\begin{tabular}{|c|c|c|c|c|c|c|c|}
\hline Source & Study & Type $^{a}$ & Period $^{b}$ & Cases $^{c}$ & End-point $^{d}$ & RR/OR (95\% Cl) & Adjustment factors $^{\mathrm{e}}$ \\
\hline Bolinder et al. [41] & Construction Workers & PC & 1971-74/1985 & 172 & $\mathrm{~F}$ & $1.35(1.13-1.62)^{f}$ & age, res \\
\hline Haglund et al. [42] & Survey of living conditions & PC & $1988-89 / 2003$ & 28 & $F+N F$ & $0.77(0.51-1.15)^{g, h}$ & age, exe, hea, ill, res, ses \\
\hline Wennberg et al. [43] & VIP' and MONICA & NCC & 1985-99/1999 & 21 & $F+N F$ & $0.82(0.46-1.43)$ & age, bmi, cho, edu, lei, phy \\
\hline Huhtasaari et al. [44] & $1^{\text {st }}$ MONICA study & $\mathrm{CC}$ & $1989-91$ & 59 & $F+N F$ & $0.89(0.62-1.29)^{g, h}$ & age \\
\hline Huhtasaari et al. [45] & $2^{\text {nd }}$ MONICA study & $\mathrm{CC}$ & $1991-93$ & 59 & $F+N F$ & $0.93(0.65-1.34)^{\mathrm{f}, \mathrm{h}}$ & none \\
\hline Hergens et al. [46] & Two counties & $\mathrm{CC}$ & 1992-94 & 10 & $F+N F$ & $0.73(0.35-1.50)$ & age, res \\
\hline \multirow[t]{8}{*}{ Hansson et al. [20] } & Construction Workers ${ }^{k}$ & PC & $1978-93 / 20 y$ & 309 & $F+N F$ & $1.01(0.90-1.14)$ & age \\
\hline & Malmö diet and cancer' & PC & 1991-96/13y & 4 & $F+N F$ & $1.00(0.37-2.70)$ & age \\
\hline & MONICA N.Sweden & PC & 1986-2004/11y & 7 & $F+N F$ & $0.77(0.35-1.69)$ & age \\
\hline & National March Cohort & PC & 1997/9y & 0 & $F+N F$ & - & age \\
\hline & SALT ${ }^{\mathrm{m}}$ & PC & 1998-2002/8y & 21 & $F+N F$ & $1.56(0.98-2.48)$ & age \\
\hline & Stockholm Public Health & PC & $2002 / 5 y$ & 5 & $F+N F$ & $1.21(0.48-3.08)$ & age \\
\hline & Scania Public Health & PC & 1991-2000/8y & 8 & $F+N F$ & $1.90(0.90-4.00)$ & age \\
\hline & WOLF $^{n}$ & PC & $1992-98 / 9 y$ & 2 & $F+N F$ & $3.30(0.63-17.1)$ & age \\
\hline \multirow[t]{2}{*}{ Total } & 13 estimates & & & & Fixed $^{\circ}$ & $1.07(0.98-1.16)$ & Het $p=0.06$ \\
\hline & & & & & Random $^{p}$ & $1.06(0.91-1.23)$ & \\
\hline \multirow[t]{2}{*}{ Excluding [41] } & 12 estimates & & & & Fixed $^{\circ}$ & $1.00(0.91-1.10)$ & Het $p=0.34$ \\
\hline & & & & & Random ${ }^{p}$ & $1.00(0.88-1.13)$ & \\
\hline
\end{tabular}

${ }^{\mathrm{a}} \mathrm{PC}=$ prospective cohort, $\mathrm{NCC}=$ nested case-control, $\mathrm{CC}=$ case-control.

${ }^{b}$ For case-control studies, the period of interviewing is shown. For prospective cohort or nested case-control studies, the baseline period is shown before the /, and either the final year of follow-up or, where this is not available, the mean person-years of follow-up after the $/$.

${ }^{\mathrm{C}}$ The number of cases exposed to snus.

${ }^{\mathrm{d}} \mathrm{F}=$ fatal, $\mathrm{NF}=$ non-fatal.

${ }^{\mathrm{e}}$ Abbreviations used: bmi body mass index, cho cholesterol level, edu education, exe exercise, hea self reported health, ill longstanding illness, lei leisure time, phy physical activity, res area of residence, ses socioeconomic status.

Estimated from data in source article.

${ }^{g}$ Estimate is for current v non-current snus users.

hEstimate is for non-current smokers.

'VIP = Vasterbötten Intervention Program.

${ }^{\mathrm{j}}$ MONICA = Multinational Monitoring of trends and determinants in Cardiovascular disease.

${ }^{\mathrm{k}}$ Results supersede those reported earlier [38].

'Results supersede those reported earlier [39].

${ }^{m_{S}} \mathrm{SATT}=$ Screening across the lifespan twin study, results supersede those reported earlier [40].

${ }^{n}$ WOLF $=$ Work, lipids and fibrinogen.

o"Fixed" - the result of the fixed effect meta-analysis is shown on the right followed by the between-study heterogeneity $p$ value ("Het $p$ ").

"Random" - the result of the random-effects meta-analysis is shown on the right.

person-years of follow-up. The results seem consistent with an earlier report from this study [38] which reported a significantly increased risk in never smokers associated with current snus use for fatal cases (RR 1.32, 95\% CI 1.08-1.61) but a non-significantly decreased risk for non-fatal cases (RR 0.70, 95\% CI 0.48-1.02). It should be noted that there are four other studies $[42,43,45,46]$ which have separately reported results for fatal cases and either non-fatal cases or all cases combined. While (see Table 2) the estimates for fatal cases from those studies all have wide variability, it is interesting to note that in all these studies risks are also above 1.0 for fatal cases and below 1.0 for non-fatal cases. The combined RR/OR estimated from the five studies is 1.31 (95\% CI 1.09 1.58) for fatal cases and 0.89 (95\% CI 0.79-1.00) for nonfatal cases, with no evidence of heterogeneity. Taken at face-value, these results suggest that current snus use in never smokers may be associated with a slightly reduced risk of non-fatal AMI/IHD, but with an increased risk of fatal cases. Whether the increased risk of fatal cases reflects a direct effect of snus or an effect of confounding (e.g. a tendency for snus users to report disease later or have less medical care when they do) requires further investigation. In any case, it is evident that any true increase in risk of AMI resulting from snus use, if it exists, is very much less than that from smoking.

Another recent relevant publication [25] investigated the relationship between snus and risk of heart failure based on results from two Swedish cohorts. One was the Construction Workers Study, where an analysis in never smokers including 75 cases in current snus users reported a marginally significant RR of 1.28 (95\% CI 1.00-1.64) after adjustment for age, BMI, region and AMI before baseline. However, no dose-response was 
Table 2 RR/OR of IHD/AMI for current (vs. never) snus use - by case fatality ${ }^{\text {a }}$

\begin{tabular}{|c|c|c|c|}
\hline Source & Fatal & Non-fatal ${ }^{b}$ & Ratio fatal to non-fatal \\
\hline$\overline{\text { Haglund et al. ([42] })^{d}}$ & $1.15(0.54-2.41)$ & $0.65(0.40-1.06)$ & $1.77(0.72-4.31)$ \\
\hline Wennberg et al. ([43]) & $1.12(0.38-3.29)$ & $0.73(0.37-1.42)$ & $1.54(0.43-5.42)$ \\
\hline Huhtasaari et al. $([45])^{f}$ & $1.50(0.45-5.03)$ & $0.36(0.15-0.85)$ & $4.22(0.96-18.64)$ \\
\hline Hergens et al. ([46]) & $1.70(0.48-5.50)$ & $0.59(0.25-1.40)$ & $2.88(0.65-12.82)$ \\
\hline Hergens et al. ([38]) & $1.32(1.08-1.61)$ & $0.94(0.83-1.06)$ & $1.40(1.11-1.77)$ \\
\hline Total $^{9}$ & $1.31(1.09-1.58)$ & $0.89(0.79-1.00)$ & $1.48(1.19-1.84)$ \\
\hline
\end{tabular}

${ }^{\mathrm{a} R R / O R s}$ are based on data for male never smokers. Adjustment factors are as in Table 1 except where stated.

${ }^{b}$ For the first three studies, RR (CI) for non-fatal cases have been estimated from those for fatal cases and for combined fatal and non-fatal cases.

${ }^{c} \mathrm{RR}(\mathrm{Cl})$ for the ratio estimated from those for fatal and non-fatal cases.

dEstimates are for current $v$ non-current snus use, based on non-current smokers.

${ }^{\mathrm{e}}$ Fatal cases are fatal within 28 days of onset.

fWhereas the results in Table 1 for this study are unadjusted results for non-current smokers comparing current and never snus users, the results in Table 2 are results for non-current smokers comparing ever and never regular snus users with adjustment for hypertension, education, marital status, diabetes, cholesterol and family history of AMI.

${ }^{9}$ Fixed-effects estimates. There was no evidence of heterogeneity; with $p=0.98$ for fatal, $p=0.10$ for non-fatal and $p=0.55$ for the ratio.

seen with the daily amount of snus used. The other was the Uppsala Longitudinal Study. Here, the analysis included smokers and nonsmokers, and included 14 heart failure cases in snus users, the association again being marginally significant (RR 2.08, 95\% CI 1.03-4.22). As the authors pointed out, the findings "need confirmation in further studies and underlying mechanisms remain to be elucidated".

\section{Periodontitis and dental caries}

The earlier review [17] briefly summarized evidence related to various aspects of non-neoplastic oral disease. Though there were some reports of increased risks of gingival disease [47] or of dental caries [48], more studies showed no effects on such diseases [49-52] and it was evident that any association of snus use with periodontal and gingival disease or with dental caries was not established.

These conclusions are supported by two recent publications [26,27] based on stratified random samples of the population of Jönköping, Sweden aged 20, 30, 40, 50, 60 and 70 years, taken in 1983, 1993 and 2003. After adjusting for age, sex and sociodemographic variables snus users were found to have no increased risk of periodontitis [26] or of dental caries [27].

\section{Discussion}

Based on my previous review [17], I concluded that snus use is clearly much safer than smoking, and that any effects of snus use on the risk of cancer or CID, if they exist, are probably no more than $1 \%$ of that of smoking. I also noted that switching to using snus should improve the health prospects of those smokers unable or unwilling to relinquish nicotine, and that there is no good evidence that introducing snus into a population would encourage smoking initiation or discourage cessation.
While this update does not consider evidence relating snus use to initiation or cessation of smoking, it does provide further information on possible health effects associated with snus use. As regards neoplastic conditions, recent evidence extends the list of those unassociated with snus use to include colorectal cancer [22] and acoustic neuroma [24], and, for pancreatic cancer [19] adds further weight to undermine the claims [12,53] of an adverse effect of snus use, claims that have already been shown to be unsoundly based [15-17]. The recent publication [21], which reports some cases of oral cancers occurring at the site where snus has been placed, does not provide evidence of effect in the absence of control data on the distribution of sites of oral cancer among all snus users and among non-users. Here, the epidemiological evidence suggests that if there is an increased risk it is small, and much less than that associated with smoking. Despite the lack of evidence that snus use increases risk of cancer, the recent observation [23] that it is associated with poorer survival demands further investigation.

New publications on periodontitis [26] or dental caries [27] also add to the evidence that snus use has no effect on non-neoplastic oral lesions, other than causing "snuff-dippers lesion" [18], which has not been shown to be predictive of cancer.

Although the evidence remains clear that effects of snus use on risk of CID, if they exist, are much less than those of smoking, recent publications have provided evidence of increased risk in snus users of heart failure [25] and of case fatality from AMI [20]. More evidence on both these issues is needed. For AMI, this review presents evidence from five studies $[38,42,43,45,46]$ that snus use, in never smokers, is associated with a somewhat reduced risk of non-fatal AMI, but with an increased risk of fatal AMI. The extent to which this difference reflects true effects of snus or uncontrolled confounding requires further investigation. 


\section{Conclusions}

Adverse health effects of snus use have not been clearly identified. The recent literature strengthens the evidence that any cancer risk (including that of pancreatic cancer) is at most minimal, and certainly much less than that associated with smoking. However, it does suggest that snus use might adversely affect survival from cancer. Although there is little evidence that snus use is associated with onset of AMI or stroke, reports of an increased risk of fatal AMI require further investigation.

\section{Abbreviations}

AMI: Acute myocardial infarction; BMl: Body mass index; Cl: Confidence interval; CID: Circulatory disease; IHD: Ischaemic heart disease; MONICA: Monitoring of cardiovascular disease; OR: Odds ratio; RR: Relative risk

\section{Competing interests}

The author is a long-term consultant to the tobacco industry. However, this is an independent scientific assessment, the views expressed being those of the author alone.

\section{Authors' contributions}

PNL was responsible for planning the study and writing the paper.

\section{Acknowledgements}

This update was supported by Swedish Match, with some of the earlier reviews underpinning it supported by Philip Morris Products and the European Smokeless Tobacco Council. The study sponsor had no involvement in the planning, execution or writing of this manuscript or the decision to submit it for publication. Thanks are due to Pauline Wassell, Diana Morris and Yvonne Cooper for typing, and obtaining relevant literature, and to John Fry for commenting on drafts.

Received: 4 December 2012 Accepted: 2 December 2013 Published: 6 December 2013

\section{References}

1. Brunnemann KD, Hoffman D: Chapter 3. Carcinogenesis. Chemical composition of smokeless tobacco products. In Smokeless Tobacco or Health. An international perspective. Bethesda, MD: US Department of Health and Human Services, National Institutes of Health, National Cancer Institute; 1992:96-108. [Smoking and tobacco control. Monograph No. 2.] NIH Publication No. 92-3461.

2. Brunnemann KD, Qi J, Hoffman D: Aging of Oral Moist Snuff and the Yields of Tobacco-Specific N-Nitrosamines (TSNA), Progress Report. American Health Foundation; 2001

3. International Agency for Research on Cancer: Smokeless Tobacco and Some Tobacco-Specific N-Nitrosamines. Volume 89. Lyon, France: IARC; 2007. (Accessed Oct 2010). [IARC Monographs on the evaluation of carcinogenic risks to humans.] http://monographs.iarc.fr/ENG/Monographs/vol89/mono89.pdf.

4. Weitkunat R, Sanders E, Lee PN: Meta-analysis of the relation between European and American smokeless tobacco and oral cancer. BMC Public Health 2007, 7:334

5. Holm H, Jarvis MJ, Russell MAH, Feyerabend C: Nicotine intake and dependence in Swedish snuff takers. Psychopharmacology (Berl) 1992 108:507-511.

6. Bolinder G, Norén A, Wahren J, de Faire U: Long-term use of smokeless tobacco and physical performance in middle-aged men. Eur J Clin Invest 1997, 27:427-433.

7. Bolinder G, Norén A, de Faire U, Wahren J: Smokeless tobacco use and atherosclerosis: an ultrasonographic investigation of carotid intima media thickness in healthy middle-aged men. Atherosclerosis 1997, 132:95-103.

8. Bolinder $\mathrm{G}$, de Faire $\mathrm{U}$ : Ambulatory $24-\mathrm{h}$ blood pressure monitoring in healthy, middle-aged smokeless tobacco users, smokers, and nontobacco users. Am J Hypertens 1998, 11:1153-1163.
9. Eliasson M, Lundblad D, Hägg E: Cardiovascular risk factors in young snuff-users and cigarette smokers. J Intern Med 1991, 230:17-22.

10. Agewall S, Persson B, Lindstedt G, Fagerberg B: Smoking and use of smokeless tobacco in treated hypertensive men at high coronary risk: utility of urinary cotinine determination. Br J Biomed Sci 2002, 59:145-149.

11. Wennmalm A, Benthin G, Granström EF, Persson L, Petersson A-S, Winell S: Relation between tobacco use and urinary excretion of thromboxane $A_{2}$ and prostacyclin metabolites in young men. Circulation 1991, 83:1698-1704

12. Scientific Committee on Emerging and Newly Identified Health Risks (SCENIHR): Health Effects of Smokeless Tobacco Products. Brussels: European Commission, Health \& Consumer Protection Directorate-General; 2008. (Accessed Oct 2010). http://ec.europa.eu/health/ph_risk/committees/04 scenihr/docs/scenihr_o_013.pdf.

13. Lee PN: Circulatory disease and smokeless tobacco in Western populations: a review of the evidence. Int J Epidemiol 2007, 36:789-804.

14. Kallischnigg G, Weitkunat $R$, Lee PN: Systematic review of the relation between smokeless tobacco and non-neoplastic oral diseases in Europe and the United States. BMC Oral Health 2008, 8:13.

15. Sponsiello-Wang Z, Weitkunat R, Lee PN: Systematic review of the relation between smokeless tobacco and cancer of the pancreas in Europe and North America. BMC Cancer 2008, 8:356.

16. Lee PN, Hamling JS: Systematic review of the relation between smokeless tobacco and cancer in Europe and North America. BMC Med 2009, 7:36.

17. Lee PN: Summary of the epidemiological evidence relating snus to health. Regul Toxicol Pharmacol 2011, 59:197-214.

18. Axéll T, Mörnstad $H$, Sundström B: The relation of the clinical picture to the histopathology of snuff dipper's lesions in a Swedish population. J Oral Pathol 1976, 5:229-236.

19. Bertuccio P, La Vecchia C, Silverman DT, Petersen GM, Bracci PM, Negri E, Li D, Risch HA, Olson SH, Gallinger S, Miller AB, Bueno-de-Mesquita HB, Talamini R, Polesel J, Ghadirian P, Baghurst PA, Zatonski W, Fontham ET, Bamlet WR, Holly EA, Lucenteforte E, Hassan M, Yu H, Kurtz RC, Cotterchio M, Su J, Maisonneuve P, Duell EJ, Bosetti C, Boffetta P: Cigar and pipe smoking, smokeless tobacco use and pancreatic cancer: an analysis from the international pancreatic cancer case-control consortium (PanC4). Ann Oncol 2011, 22:1420-1426.

20. Hansson J, Galanti MR, Hergens M-P, Fredlund P, Ahlbom A, Alfredsson L, Bellocco R, Eriksson M, Hallqvist J, Hedblad B, Jansson J-H, Nilsson P, Pedersen N, Lagerros YT, Östergren P-O, Magnusson C: Use of snus and acute myocardial infarction: pooled analysis of eight prospective observational studies. Eur J Epidemiol 2012, 27:771-779.

21. Hirsch JM, Wallström M, Carlsson A-P, Sand L: Oral cancer in Swedish snuff dippers. Anticancer Res 2012, 32:3327-3330.

22. Nordenvall C, Nilsson PJ, Ye W, Nyrén O: Smoking, snus use and risk of right- and left-sided colon, rectal and anal cancer: a 37 year follow-up study. Int J Cancer 2011, 128:157-165.

23. Nordenvall C, Nilsson PJ, Ye W, Andersson TML, Nyrén O: Tobacco use and cancer survival: a cohort study of 40,230 Swedish male construction workers with incident cancer. Int J Cancer 2013, 132:155-161.

24. Palmisano S, Schwartzbaum J, Prochazka M, Pettersson D, Bergenheim T, Florentzson R, Harder H, Mathiesen T, Nyberg G, Siesjö P, Feychting M: Role of tobacco use in the etiology of acoustic neuroma. Am J Epidemiol 2012, 175:1243-1251.

25. Arefalk G, Hergens M-P, Ingelsson E, Ärnlöv J, Michaëlsson K, Lind L, Ye W, Nyrén O, Lambe M, Sundström J: Smokeless tobacco (snus) and risk of heart failure: results from two Swedish cohorts. Eur J Prev Cardiol 2012, 19:1120-1127.

26. Hugoson A, Rolandsson M: Periodontal disease in relation to smoking and the use of Swedish snus: epidemiological studies covering 20 years (1983-2003). J Clin Periodontol 2011, 38:809-816

27. Hugoson A, Hellqvist L, Rolandsson M, Birkhed D: Dental caries in relation to smoking and the use of Swedish snus: epidemiological studies covering 20 years (1983-2003). Acta Odontol Scand 2012, 70:289-296.

28. Luo J, Ye W, Zendehdel K, Adami J, Adami H-O, Boffetta P, Nyrén O: Oral use of Swedish moist snuff (snus) and risk of cancer of the mouth, lung, and pancreas in male construction workers: a retrospective cohort study. Lancet 2007, 369:2015-2020.

29. Boffetta P, Aagnes B, Weiderpass E, Andersen A: Smokeless tobacco use and risk of cancer of the pancreas and other organs. Int J Cancer 2005, 114:992-995. 
30. Rutavist LE, Lewin F: Flawed methods [Letter]. Int J Cancer 2006, 118:1581.

31. Nilsson R: Possible carcinogenicity of smokeless tobacco [Letter]. Int J Cancer 2006, 118:1582-1583.

32. Ramström L: Re: "smokeless tobacco use and risk of cancer of the pancreas and other organs" by boffetta et al [letter]. Int J Cancer 2006, 118:1584.

33. Rodu B, Cole P: A deficient study of smokeless tobacco use and cancer [Letter]. Int J Cancer 2006, 118:1585

34. Nyrén O, Lambe M, Ye W, Adami H-O: Are cohort data on smokeless tobacco use and pancreatic cancer confounded by alcohol use? [Letter]. Ann Oncol 2011, 22:1930-1931.

35. Luo J, Iwasaki M, Inoue M, Sasazuki S, Otani T, Ye W, Tsugane S: Body mass index, physical activity and the risk of pancreatic cancer in relation to smoking status and history of diabetes: a large-scale population-based cohort study in Japan. The JPHC study. Cancer Causes Control 2007, 18:603-612.

36. Rodu B, Jansson C: Smokeless tobacco and oral cancer: a review of the risks and determinants. Crit Rev Oral Biol Med 2004, 15:252-263.

37. Roosaar A, Johansson ALV, Sandborgh-Englund G, Nyrén O, Axéll T: A longterm follow-up study on the natural course of snus-induced lesions among Swedish snus users. Int J Cancer 2006, 119:392-397.

38. Hergens M-P, Alfredsson L, Bolinder G, Lambe M, Pershagen G, Ye W: Longterm use of Swedish moist snuff and the risk of myocardial infarction amongst men. J Intern Med 2007, 262:351-359.

39. Janzon E, Hedblad B: Swedish snuff and incidence of cardiovascular disease. A population-based cohort study. BMC Cardiovasc Disord 2009, 9:21.

40. Hansson J, Pedersen NL, Galanti MR, Andersson T, Ahlbom A, Hallqvist J, Magnusson C: Use of snus and risk for cardiovascular disease: results from the Swedish twin registry. J Intern Med 2009, 265:717-724.

41. Bolinder G, Alfredsson L, Englund A, de Faire U: Smokeless tobacco use and increased cardiovascular mortality among Swedish construction workers. Am J Public Health 1994, 84:399-404.

42. Haglund B, Eliasson M, Stenbeck M, Rosén M: Is moist snuff use associated with excess risk of IHD or stroke? A longitudinal follow-up of snuff users in Sweden. Scand J Public Health 2007, 35:618-622.

43. Wennberg $P$, Eliasson $M$, Hallmans $G$, Johansson L, Boman $K$, Jansson J-H: The risk of myocardial infarction and sudden cardiac death amongst snuff users with or without a previous history of smoking. I Intern Med 2007, 262:360-367.

44. Huhtasaari F, Asplund K, Lundberg V, Stegmayr B, Wester PO: Tobacco and myocardial infarction: is snuff less dangerous than cigarettes? BMJ 1992, 305:1252-1256.

45. Huhtasaari F, Lundberg V, Eliasson M, Janlert U, Asplund K: Smokeless tobacco as a possible risk factor for myocardial infarction: a populationbased study in middle-aged men. J Am Coll Cardiol 1999, 34:1784-1790.

46. Hergens M-P, Ahlbom A, Andersson T, Pershagen G: Swedish moist snuff and myocardial infarction among men. Epidemiology 2005, 16:12-16.

47. Montén U, Wennström JL, Ramberg P: Periodontal conditions in male adolescents using smokeless tobacco (moist snuff). J Clin Periodontol 2006, 33:863-868.

48. Hirsch JM, Livian G, Edward S, Noren JG: Tobacco habits among teenagers in the city of Göteborg, Sweden, and possible association with dental caries. Swed Dent J 1991, 15:117-123.

49. Bergström J, Keilani H, Lundholm C, Rådestad U: Smokeless tobacco (snuff) use and periodontal bone loss. J Clin Periodontol 2006, 33:549-554.

50. Modéer T, Lavstedt S, Åhlund C: Relation between tobacco consumption and oral health in Swedish schoolchildren. Acta Odontol Scand 1980 38:223-227.

51. Rolandsson M, Hellqvist L, Lindqvist $L$, Hugoson A: Effects of snuff on the oral health status of adolescent males: a comparative study. Oral Health Prev Dent 2005, 3:77-85.

52. Wickholm S, Söder P-Ö, Galanti MR, Söder B, Klinge B: Periodontal disease in a group of Swedish adult snuff and cigarette users. Acta Odontol Scand 2004, 62:333-338.

53. Boffetta P, Hecht S, Gray N, Gupta P, Straif K: Smokeless tobacco and cancer. Lancet Oncol 2008, 9:667-675.

doi:10.1186/1477-7517-10-36

Cite this article as: Lee: Epidemiological evidence relating snus to health - an updated review based on recent publications. Harm Reduction Journal 2013 10:36.

\section{Submit your next manuscript to BioMed Central and take full advantage of:}

- Convenient online submission

- Thorough peer review

- No space constraints or color figure charges

- Immediate publication on acceptance

- Inclusion in PubMed, CAS, Scopus and Google Scholar

- Research which is freely available for redistribution 